\title{
Flow Characteristics in an Inter-Turbine Duct Under Off Design Conditions
}

\author{
A. Lakshya Kumar and A. M. Pradeep \\ Department of Aerospace Engineering \\ Indian Institute of Technology Bombay, Powai, Mumbai, India - 400076 \\ a.lakshya@aero.iitb.ac.in; ampradeep@aero.iitb.ac.in
}

\begin{abstract}
In the present numerical study, flow characteristics of an aggressive inter-turbine duct under design and off-design inflow conditions, are reported. Two duct geometries (1) un-strutted and (2) strutted are considered. An un-strutted duct with sector angle of $20^{\circ}$ and a strutted duct with $40^{\circ}$ sector angle are analyzed. The performance of the duct is evaluated using static pressure recovery and total pressure loss. For simulating off design conditions, the duct inlet boundary is imposed with a typical tip leakage profile (reminiscent of the exit flow from the preceding high pressure turbine stage) and swirl. The swirl is varied between $10^{\circ}$ to $30^{\circ}$. Under off-design conditions, the un-strutted duct shows only marginal deviation in its performance. However, the strutted duct showed a significant increase in loss under off-design conditions.
\end{abstract}

Keywords: Inter-turbine duct, Tip leakage flow, Swirl, Off-design operation.

\section{Introduction}

The quest for performance of modern aero engines calls for high efficiency, low cost life cycle, high thrust to weight ratio, low fuel consumption, reduced noise levels and environment friendly engines. To cater all these demands in the present as well as in the future, high bypass ratio turbofan engine is a possible alternative. However, high bypass ratio requirement drives the turbofan engine to have large offsets between the high pressure (HP) and low pressure (LP) turbine. Consequently, the inter-turbine duct (ITD) connecting these two turbines becomes aggressive. Due to the aggressive geometry, the flow in the duct is subjected to massive flow separation. Apart from the flow features generating due to duct endwall curvature, flow at the inlet of the duct inherently carries HPT rotor tip leakage flow, wakes conveyed from the stator and swirling flow. These effects lead to the highly 3D flow resulting in the loss of total pressure as well as non-uniform pressure distribution at exit plane of the duct. In order to improve the performance of the duct and avoiding the adverse effects, it is essential to understand the flow physics in an inter-turbine duct.

Over the past decades several researchers have extensively investigated the effect of different parameters on the flow physics of ITD. Dominy et al. [1] experimentally analyzed the flow within an aggressive duct with and without swirl at the inlet. In a follow up work $[2,3]$ the swirling flow with wakes at the inlet were studied. It was concluded that the wakes and swirl at the inlet causes secondary flow generation leading to higher losses. Stevens et al. [4] analyzed the effect of inlet turbulence on the diffuser performance. Welborn et al. [5] investigated the flow physics of diffusing S-duct under compressible subsonic condition at Mach number 0.6. A time averaged and time dependent investigation with and without the strut in a diffusing S-duct was carried out by Norris et al [6]. It was reported that the presence of struts in the duct adversely affects the performance. Fredrik et al. [7, 8] analyzed the challenges associated with the more aggressive nature of the S-duct under design and off-design condition. The analysis looked at the influence of incoming wakes, vortices and tip leakage flow on the duct performance. Cornelia et al. [9] studied the effect of secondary flow, shocks and wakes emanating from the HPT on turning mid turbine frame (TMTF). A fair prediction of interaction among TMTF with HPT at the inlet and a contra-rotating LPT at the outlet was given. The influence of the turbine exit flow (accounting for wakes, secondary flow, swirl, tip leakage flow and trailing edge shocks in case of transonic turbine) was studied by Anisworth [10] and Miller et al. [11]. The complexities associated with highly 3D nature of the flow within the duct and vane rotor interaction mechanism were explored. Lars-Uno et al. [12,13] conducted a time-averaged investigation to explore the influence of turbulence level and turbine loading on the performance of ITD. It was reported that as the flow propagates through the duct, flow field is dominated by wakes and increased turbulence levels. High turbine loading imparts higher losses within the duct, while the 
low turbine loading does not have a significant effect. Sanz [14] and Marn et al. [15] investigated the effect of tip gap size on the ITD flow field and reported that tip gap gives the better pressure recovery. Due to inherent complexities and unpredictable nature of the onboard operating conditions, it is needed to design the ITD catering to all the possible off design conditions. Over the past few years, shape optimization and endwall contouring has been explored as a means to increase the efficiency of the ITD. Grasel et al. [16] employed optimization method and high performance CFD technique to improve the design of S-shaped ITD. Eriksson et al. $[17,18]$ carried out another design and optimization study for S-shaped duct. The optimized designed revealed some of the possible measures to reduce the duct losses and prevention of flow separation.

In the present study, numerical analysis of an aggressive duct under design and off-design operating conditions are reported. Two duct geometries have been analyzed (1) duct without strut (2) duct with strut. The duct geometries are taken from [17], which are optimized duct geometries. The objective of this study is to analyze the performance of these optimized ducts considering some possible upstream factors such as tip leakage flow profile and swirl. Based on the understanding acquired from the present analysis, it is expected to help in arriving at alternatives to improve the performance of the ITD under off-design conditions.

\section{Computational Approach}

The present computational study was carried out using the commercial CFD package, Fluent 16. Details of the geometry, grid, boundary conditions and solver are described in the following sub-sections.

\subsection{Geometry, Boundary conditions and Grid}

As mentioned earlier, two duct geometries (1) duct without strut and (2) duct with are analyzed. The un-strutted duct consisted of $20^{\circ}$ sector angle and the strutted duct with sector angle $40^{\circ}$ of a full annular duct. The length of the duct is 4.5 times the inlet radius and the radial offset between the inlet and outlet is taken $40 \%$ of the duct length. Figure [1] shows the computational domain with boundary conditions for both the duct geometries.

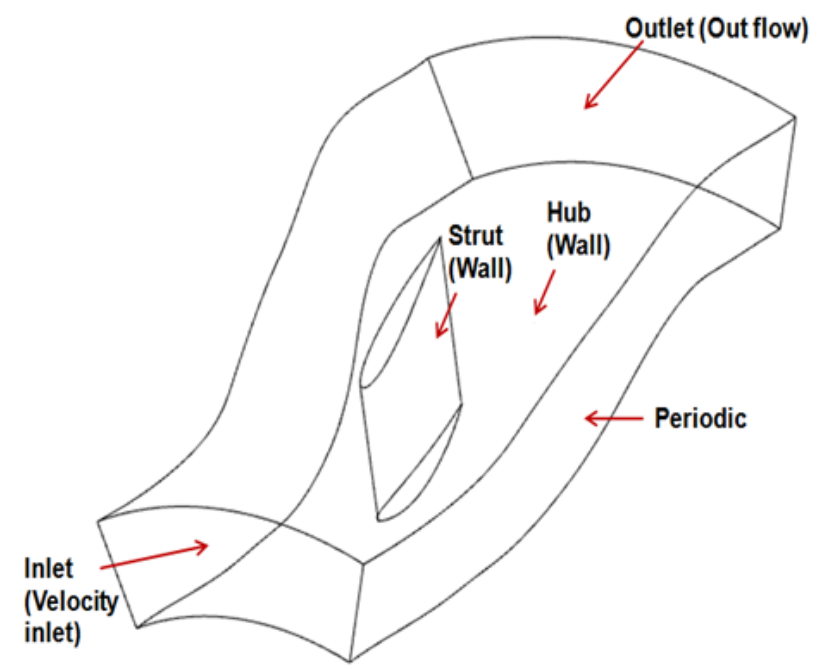

Fig.1: Computational domain for strutted duct.

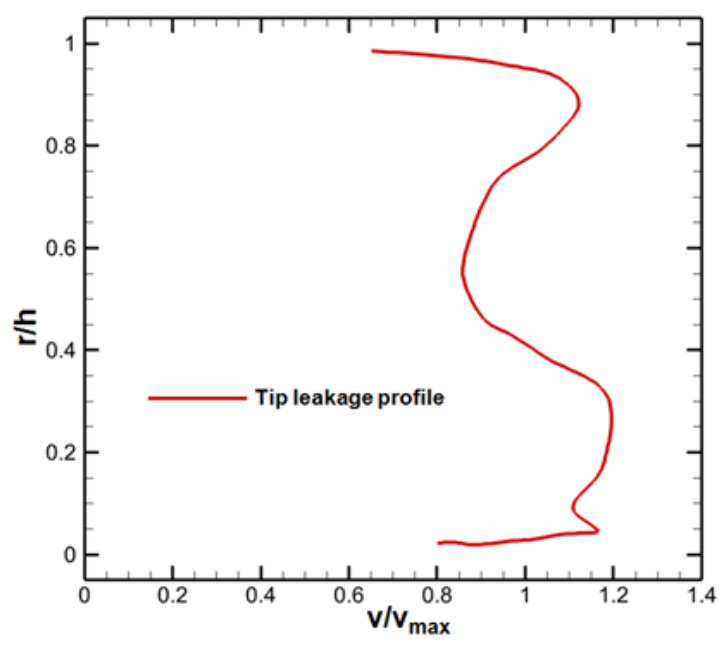

Fig. 2: Tip leakage profile.

Under the design condition, uniform velocity is specified at the inlet of the duct. The corresponding Reynolds number based on the inlet velocity and the duct diameter is $3.3 \times 10^{5}$. At the outlet, an out flow boundary is imposed. In the case of the strutted duct, the only difference is that the strut being a solid body, in the flow field is treated as wall. Under off design conditions a typical tip leakage profile as shown in Figure [2] is prescribed at the inlet. The profile is based on a typical turbine exit flow profile [19]. Another inlet condition considered is inflow with swirl. The swirl to the flow is varied between $10^{\circ}$ to $30^{\circ}$. The inlet turbulence intensity specified is $4.5 \%$. The computational domain is discretized using the ICEM CFD grid generation tool. The grid points in the domain are closely clustered to properly capture the thin boundary layer in the near end wall region. The number of grids after the grid sensitivity analysis is about 0.85 million resulting in a average wall $\mathrm{y}+$ of 3.0. The entire fluid domain is discretized by quadrilateral elements as shown in Figure [3]. 


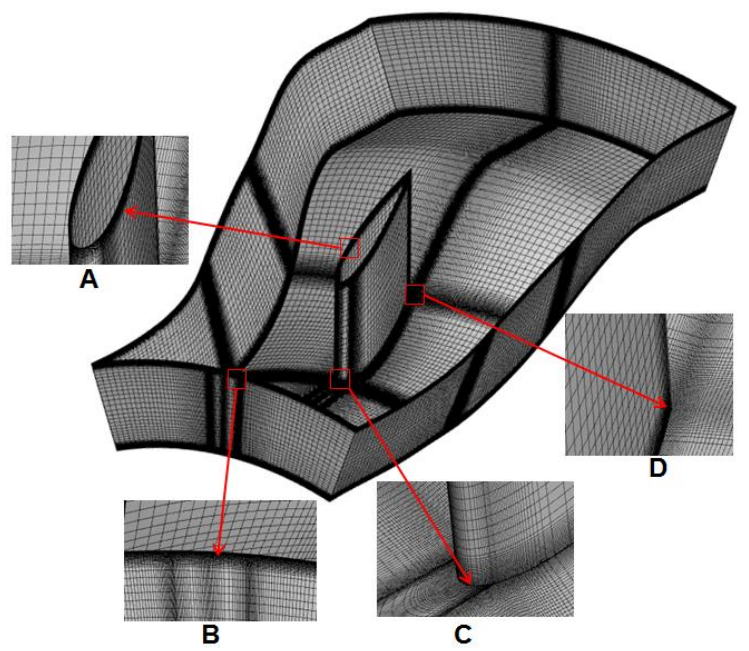

Fig. 3: Mesh generated for the computational analysis.

\section{Results and Discussion}

As discussed earlier, two duct configurations, with and without strut are analyzed. The performance of both the ducts are evaluated based on mass weighted average static pressure recovery coefficient $\left(\mathrm{C}_{\mathrm{p}}\right)$ and total pressure loss coefficient $(\zeta)$ as given in equations (1) and (2).

\begin{tabular}{|c|c|}
\hline$C_{p}=\frac{\left(P-P_{r e f}\right)}{1 / 2 \rho V^{2}}$ & (1) \\
\hline$\zeta=\frac{\left(P_{o, r e f}-P\right)}{P_{o, r e f}}$ & (2) \\
\hline
\end{tabular}

Where $P$ is the local static pressure $P_{r e f}$ is the inlet reference static pressure, $P_{o, r e f}$ is the inlet reference total pressure, $\rho$ is the fluid density and $V$ is the inlet velocity.

\subsection{Validation}

In order to check the validity of the computational scheme, the computed results are compared against the predicted results available in the literature [17]. Figures 4 and 5 show the validation of $C_{p}$ for un-strutted and strutted duct. A close agreement between both the results is observed.

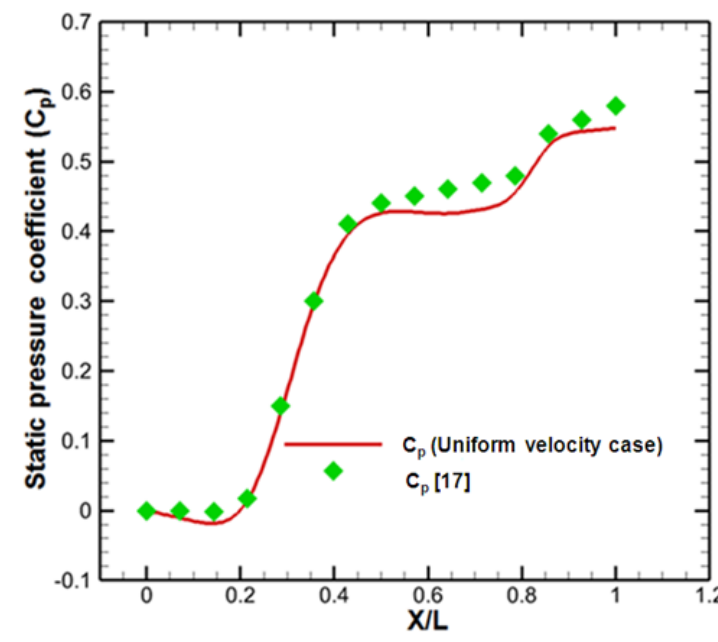

Fig. 4: $C_{p}$ validation for un-strutted duct [17].

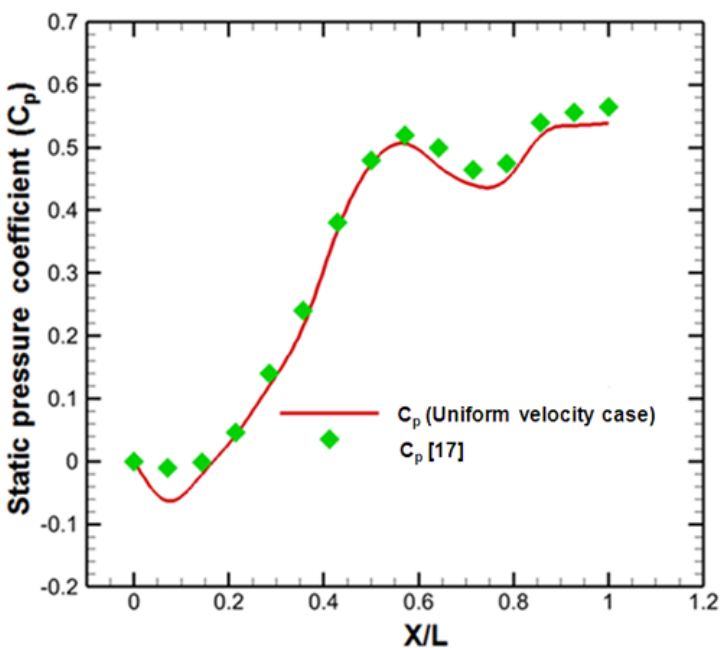

Fig. 5: $C_{p}$ validation for strutted duct [17]. 


\subsection{Un-strutted Duct}

It can be seen from Fig. 6 that the variation of $C_{p}$ with uniform velocity and TLP at the inlet has almost similar variation till the mid-section of the duct. A marginal deviation in the pressure recovery is observed after the mid-section with TLP. However, overall pressure recovery is same in both the cases. On the other hand, the total pressure losses are relatively less with TLP over the half of the duct length. This is attributed to the high-energy fluid (near the tip section) in the TLP and the flow passes through the first band of the duct without undergoing any severe separation in the endwall regions. As the flow progresses further downstream the losses are increased to about $1.5 \%$ due to the non-uniform distribution of the velocity profile over the duct cross-section, which further causes the non-uniformity in the total pressure distribution at the duct exit plane.

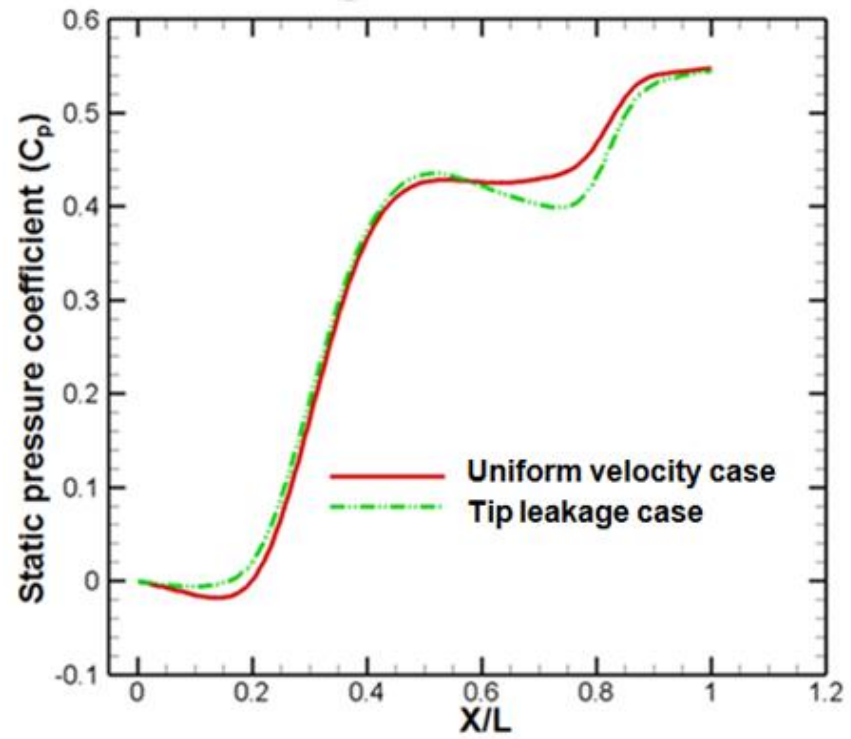

Fig. 6: $\mathrm{C}_{\mathrm{p}}$ variation with two inflow profiles.

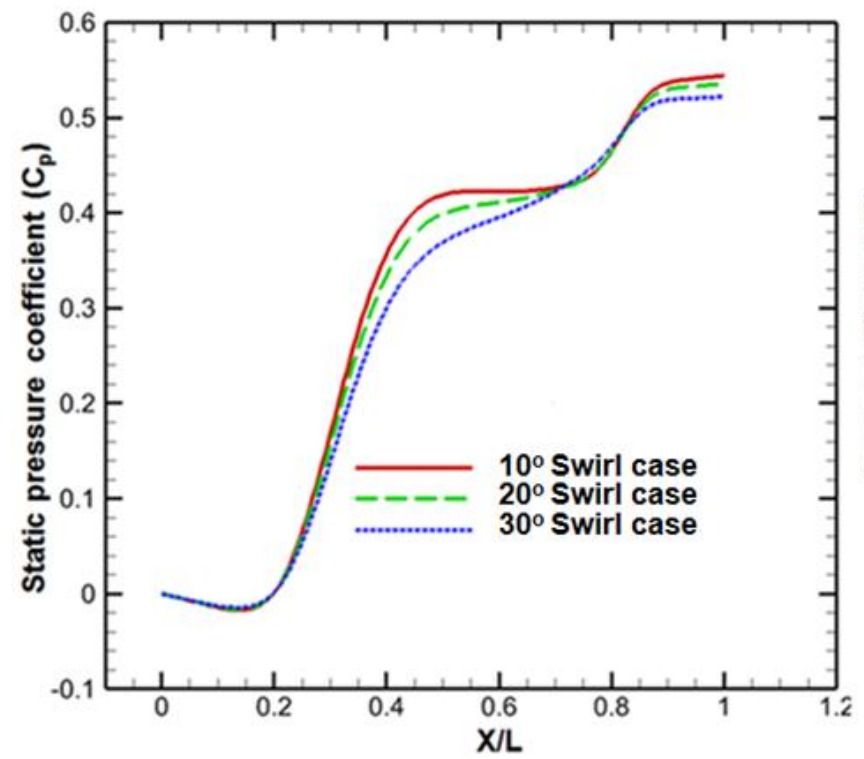

Fig. 8: Mass averaged $\mathrm{C}_{\mathrm{p}}$ variation with swirl.

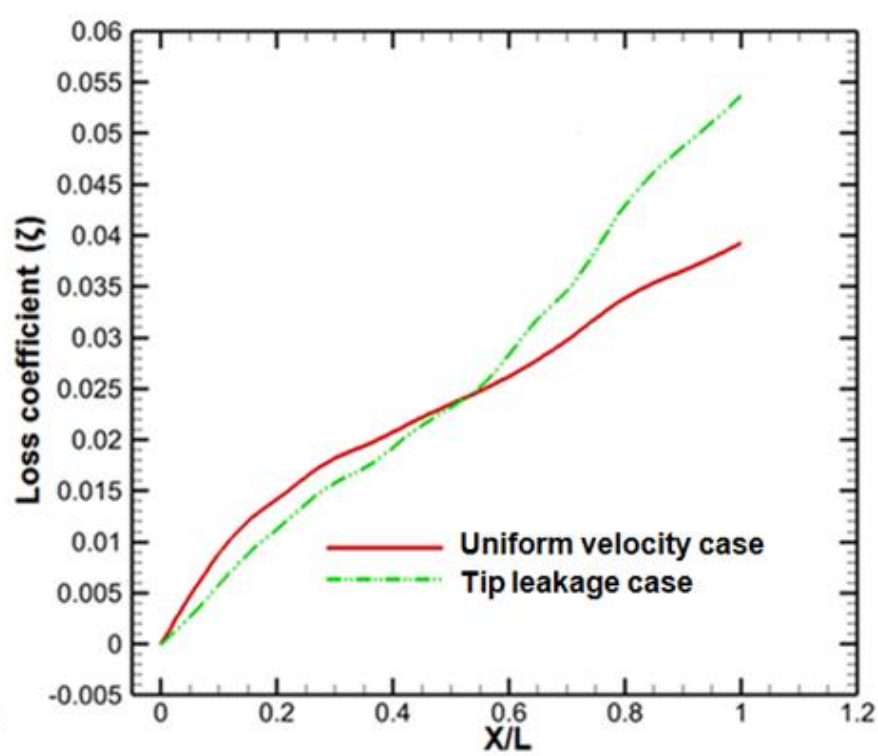

Fig. 7: $\zeta$ variation with two inflow profiles.

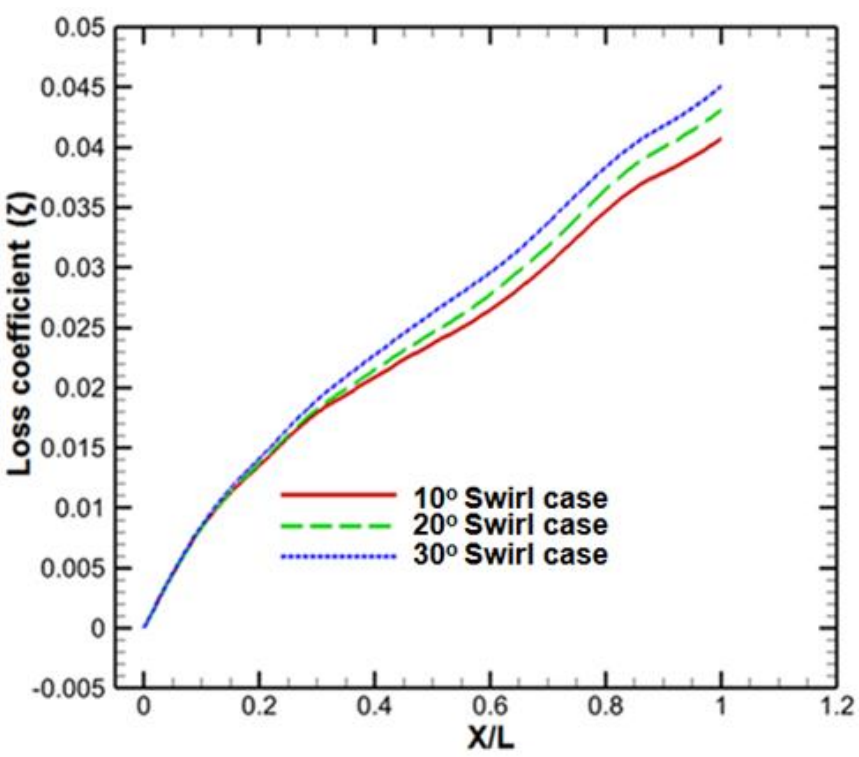

Fig. 9: Mass averaged $\zeta$ variation with swirl.

Figures 8 and 9 show the $C_{p}$ and $\zeta$ variation within the duct for swirling flow between $10^{\circ}$ to $30^{\circ}$ at the duct inlet. Similar to the uniform condition, swirling flow only causes marginal loss in the overall pressure recovery. However, due to the high flow turning in the mid-section of the duct, there is a marginal deviation in the $\mathrm{C}_{\mathrm{p}}$ with increasing swirl. The total 
pressure loss in the duct does not show much deviation. However, with the increasing swirl angle, the losses are significantly increased in the subsequent bands of the duct. Compared to the uniform velocity, the maximum swirl case results in about $5 \%$ loss in the $\mathrm{C}_{\mathrm{p}}$.

Figure 10 shows the contours of loss coefficient at the exit of the duct with inlet swirl. It can be seen that the due to inlet swirl there is non-uniform pressure distribution on the duct end-wall. Consequently, the flow is separated from the duct wall leading to generation of wakes. These wakes are conveyed further downstream causing non-uniform total pressure distribution at the exit plane. At $10^{\circ}$ swirl, the two wake regions on the hub and casing wall region can be seen. However, the losses are mostly confined to the end wall regions only. For higher swirl angle of $20^{\circ}$ and $30^{\circ}$ these wakes become thicker and cover most of the duct area causing loss of total pressure.

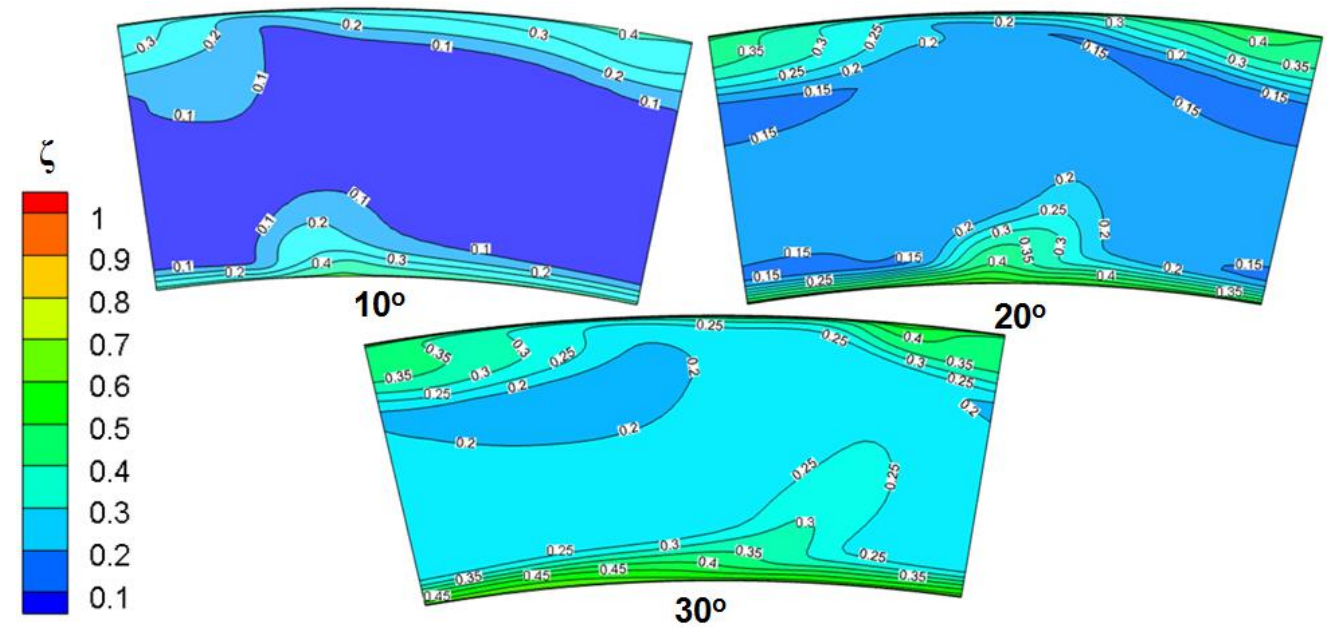

Fig.10: $\zeta$ contours at the duct exit with $10^{\circ}, 20^{\circ}$ and $30^{\circ}$ swirl at inlet.

\subsection{Strutted Duct}

Figures 11 and 12 show the variation of $\mathrm{Cp}$ and $\zeta$ for the strutted duct with uniform inlet velocity and tip leakage profile. Immediately after the duct inlet, there is a small decrease in the $\mathrm{Cp}$, which is attributed to upstream effect of the strut and a significant acceleration of the flow on the convex casing surface. At the beginning of the second bend, due to the presence of the struts, the flow stream splits. The duct with TLP owing to non-uniform velocity profile over the duct crosssection, suffers significant loss of Cp. Around $11 \%$ loss of static pressure recovery is observed with TLP. On other hand, the loss coefficient in the first bend is lower for TLP due to the fact that the high-energy fluid passes through the duct without undergoing any flow separation in the end-wall regions. However, as this high-energy flow encounters the strut, creates high turbulence in the second band leading to increase in the losses over the remaining duct length. Overall, about 5\% increase in the loss is observed for the TLP.

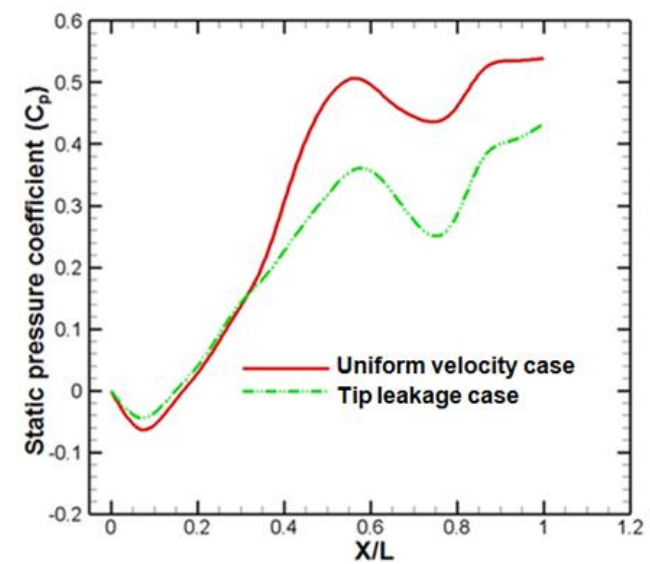

Fig. 11: Mass averaged $C_{p}$ variation with inflow profiles.

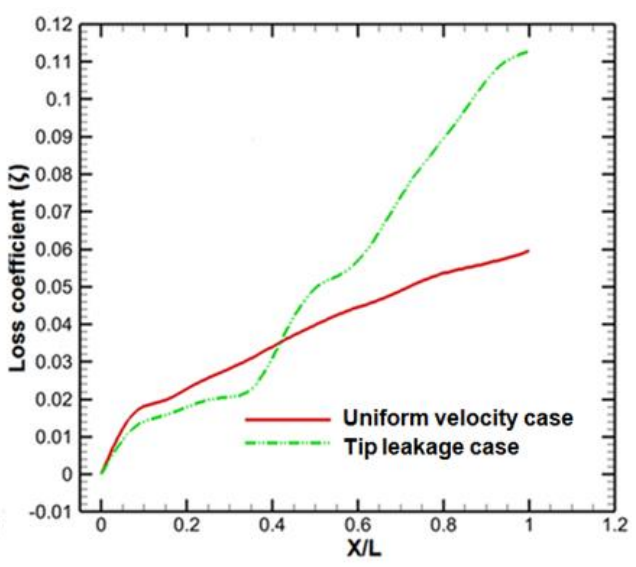

Fig. 12: Mass averaged $\zeta$ variation with inflow profiles. 
Figures 13 (a) and (b) show the $\zeta$ contours in the strutted duct. With uniform velocity, the flow is uniformly distributed over the entire duct cross-section. As the flow passes through the strut, small counter-rotating corner vortices are generated at the trailing edge of the strut in the end-wall regions. These corner vortices are strong in the casing wall region due to the concave wall surface. Further downstream, these casing vortices grow in size and merge together forming a horseshoe vortex at the exit. As can be seen in the Fig. 13 (b), the flow is non-uniformly distributed over the entire duct cross-section due to distorted velocity profile. In the region of high-energy fluid, the flow goes unaffected through the entire duct length. As can be seen, the corner vortices generated at the trailing edge are stronger giving rise to a larger horseshoe vortex. The radial pressure gradient causes these vortices to grow in size and spread over the larger cross-section near the exit plane.
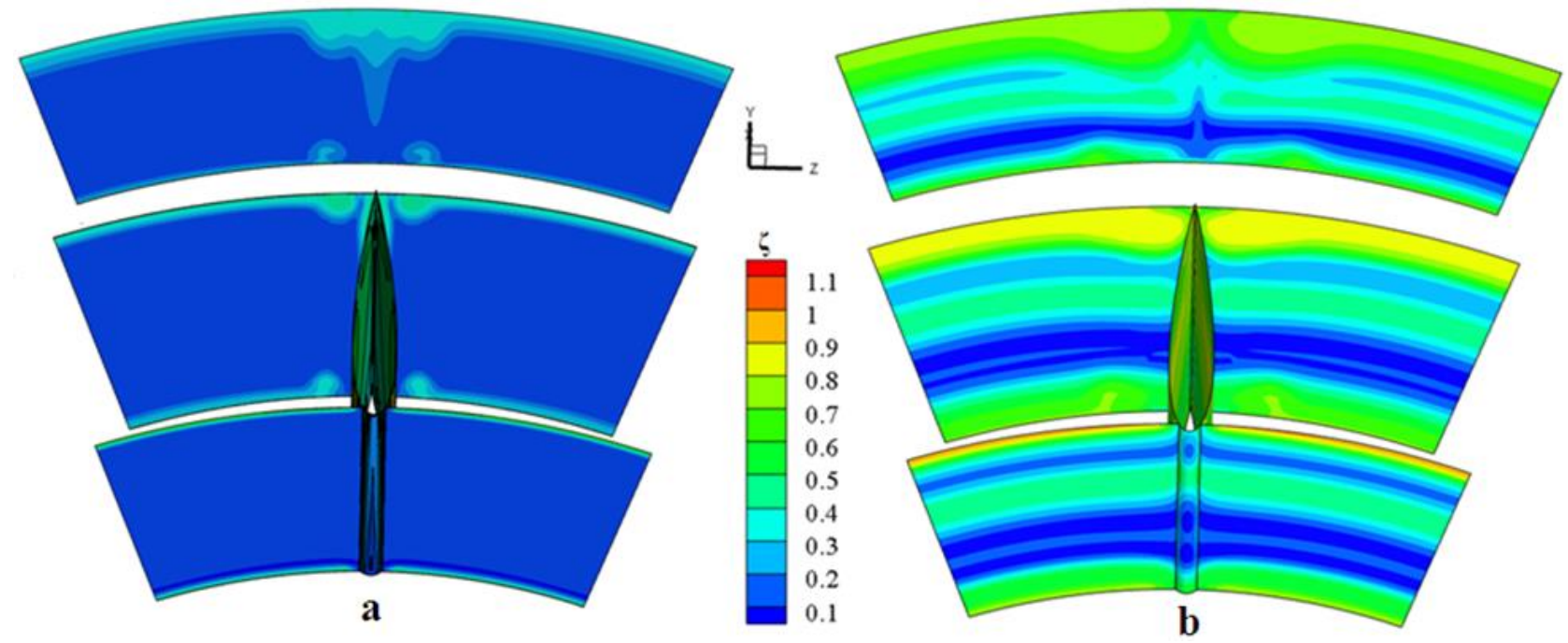

Fig. 13: $\zeta$ contours in the duct (a) with uniform velocity and (b) with TLP at inlet.

As seen in Fig. 14, with increasing swirl, there is a significant loss in static pressure recovery. At the maximum swirl of $30^{\circ}$, there is a large decrease in the $C_{p}$ due to massive flow separation in the strut region and non-uniform pressure distribution in the azimuthal as well as redial direction. This can also be seen in the total pressure loss contours in Fig. 16. Figure 15 shows the variation of loss coefficient with increasing swirl angle. At $30^{\circ}$ swirl, losses are observed to be around $9 \%$.

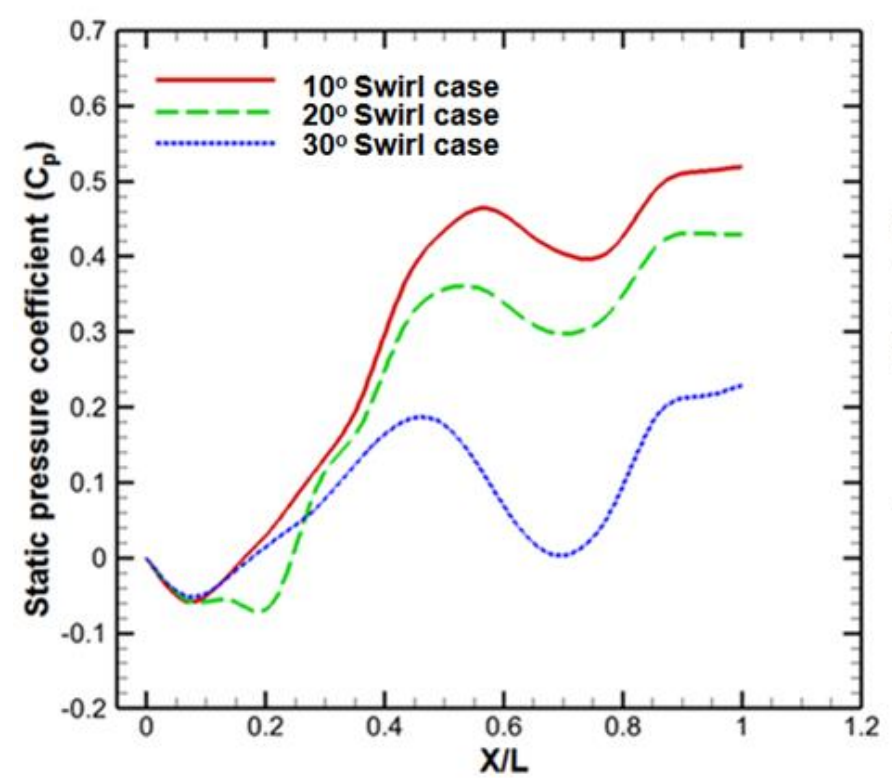

Fig. 14: Mass averaged $\mathrm{C}_{\mathrm{p}}$ variation with $10^{\circ}, 20^{\circ}$ and $30^{\circ}$ swirl.

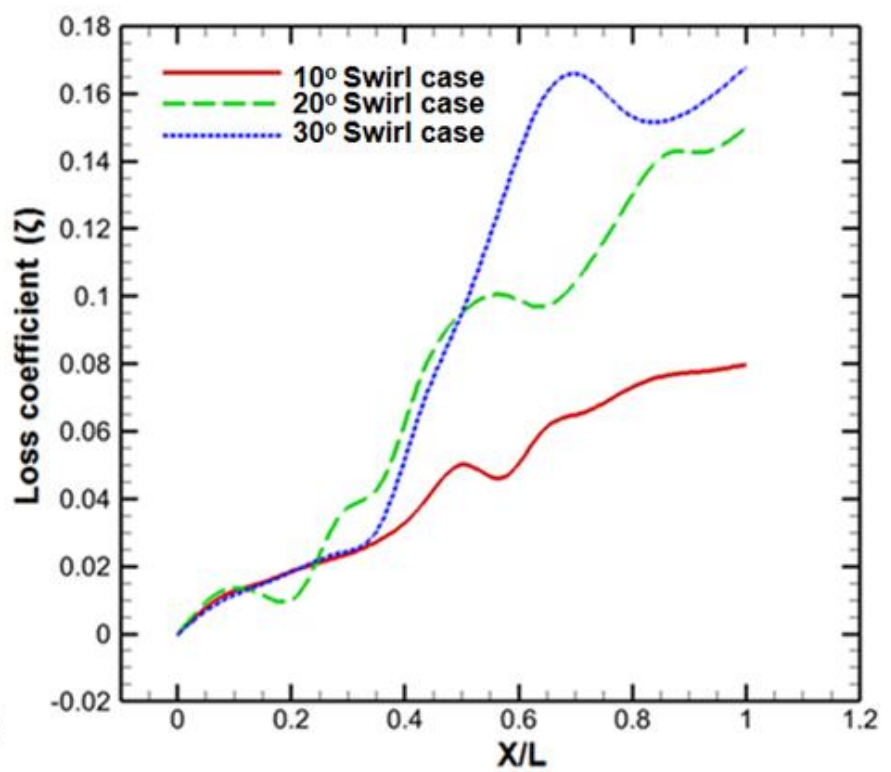

Fig. 15: Mass averaged $\zeta$ variation with $10^{\circ}, 20^{\circ}$ and $30^{\circ}$ swirl. 

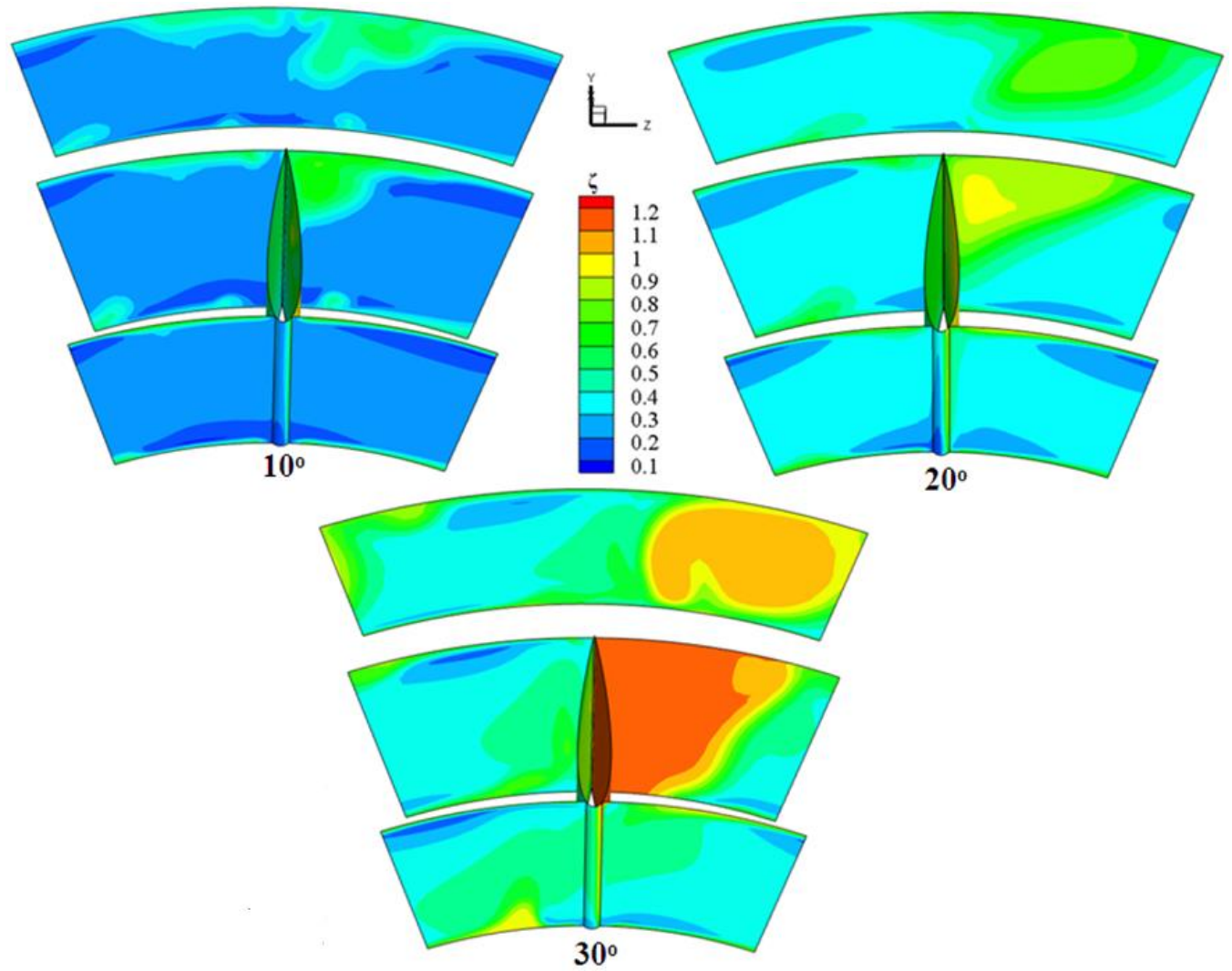

Fig. 16: $\zeta$ contours at the duct exit with $10^{\circ}, 20^{\circ}$ and $30^{\circ}$ swirl at inlet.

Figure 16 shows that at $10^{\circ}$ swirl, flow separation is observed from the strut surface. A small wake region also can be seen on the left side. Separation is essentially confined to the casing wall region. After the trailing edge, these wakes merge together forming large wake region in the downstream. At $20^{\circ}$ swirl, the separated region extends towards the casing wall due to large radial pressure gradient. With increasing swirl angle at $30^{\circ}$ and non-uniform pressure distribution in the radial direction, separation occurs from both the endwall surfaces. Consequently, larger wakes are generated which further get conveyed to the duct exit leading to loss of total pressure.

\section{Conclusions}

In the present computational study, an analysis of an inter-turbine duct is reported. The objective of this study is to understand the behaviour of the duct under different operating conditions. Two duct geometries (1) Un-strutted duct and (2) strutted duct are considered for the analysis. Both the duct geometries are analyzed under design as well as off-design conditions by imposing different conditions at the duct inlet such as tip leakage profile and swirl between $10^{\circ}$ to $30^{\circ}$. Under the off-design, un-strutted duct does not have any significant loss in the static pressure recovery; however total pressure losses are significant. Strutted duct with tip leakage profile has significant decrease in the static pressure recovery and increase in the total pressure loss. Higher performance loss in terms of static pressure recovery and total pressure is observed for the strutted duct with inlet swirl. Large flow separation from the strut surface in the casing wall region is observed. With increasing swirl angle and radial pressure gradient, this separated region extends towards the hub surface generating larger wakes near the duct exit. The separation is observed to occur near the strut and endwall corner region. It is expected that this separation can be prevented by modifying the strut endwall corner geometry.

\section{References}

[1] R. J. Dominy and D. A. Kirkham, "The influence of blade wakes on the performance of inter-turbine diffuser," in ASME 1994 International Gas Turbine and Aeroengine Congress and Exposition, Paper No. 94-GT-207, Netherlands, 1994. 
[2] R. J. Dominy and D. A. Kirkham, “The influence of swirl on the performance of inter-turbine diffuser," VDI Berichte 1186, pp. 107-122, 1995.

[3] R. J. Dominy, D. A. Kirkham, and D. A. Smith, "Flow development through inter-turbine diffuser," ASME 1994 International Gas Turbine and Aeroengine Congress and Exposition, Paper No. 96-GT-139, Birmingham, UK, 1996.

[4] S. J. Stevens and G. J. Williams, "Influence of inlet conditions on the performance of annular diffuser," Journal of Fluid Engineering, vol. 102/357, 1980.

[5] S. R .Wellborn, B. A. Reichert, and T. H. Okiishi, "An experimental investigation of the flow in a diffusing S-duct," $28^{\text {th }}$ Joint Propulsion Conference and Exhibit, Nashville TN, United States, 1992.

[6] G. Norris, R. G. Dominy, and A. D. Smith "Flow instability within a diffusing annular S-shaped duct," in $A S M E$ International Gas Turbine and Aeroengine Congress and Exhibition, Paper No. 99-GT-070, Indianapolis, Indiana, USA, 1999.

[7] C. A. Osso, F. Wallin, and T. G. Johansson "Experimental and numerical investigation of an aggressive inter-turbine duct part-1 (Flow field at design inlet condition)," in $26^{\text {th }}$ AIAA Applied Aerodynamics Conference, Honolulu, Hawaii, 2008.

[8] C. A. Osso, F. Wallin, and T. G. Johansson "Experimental and numerical investigation of an aggressive inter-turbine duct part-2 (Flow field at design inlet condition)," in $26^{\text {th }}$ AIAA Applied Aerodynamics Conference, Honolulu, Hawaii, 2008.

[9] C. Santner, B. Paradiso, and F. Malzacher, "Evolution of the flow through a turning mid turbine frame applied between a transonic HP turbine stage and a counter rotating LP turbine," in 9th European Turbomachinery Conference, Paper No. 110, Istanbul, Turkey, 2008.

[10] R. W. Ainsworth and D. L. Schultz, "A transient flow facility for the study of the thermo-fluid dynamics of a full stage turbine under engine representative conditions," in ASME International Gas Turbine Aeroengine Congress and Exposition, Paper No. 88-GT-144, Netherlands, 1988.

[11] R. J. Miller, R. W. Moss, and C. K. Horwood, "Time-resolved vane rotor interaction in a high pressure turbine stage," Journal of Turbomachinery, vol. 125-1, 2003.

[12] L. U. Axelsson and T. G. Johansson, "Experimental investigation of time averaged flow in an intermediate turbine duct," in ASME Turbo-Expo, Power for Land, See and Air, Paper No. GT2008-50829, Berlin, Germany, 2008.

[13] L. U. Axelsson and T. G. Johansson, "Evaluation of the flow in an intermediate turbine duct at off design conditions," in $26^{\text {th }}$ International Congress of the Aeronautical Sciences, (ICAS), Anchorage, Alaska, USA, 2008.

[14] W. Sanz, M. Kelterer, and R. Pecnik "Numerical investigation of the effect of tip leakage flow on an aggressive Sshaped intermediate turbine duct," in ASME Turbo-Expo, Power for Land, See and Air, Paper No. GT2009-59535, 2009.

[15] A. Marn, E. Gottlich, and F. J. Malzacher, "The effect of rotor tip clearance size onto the separated flow through a super-aggressive S-shaped intermediate turbine duct downstream of a transonic test turbine stage," in ASME TurboExpo, Power for Land, See and Air, Paper No. GT2009- 59934, 2009.

[16] J. Gräsel, M. Pierré, and J. Demolis, "Parametric inter-turbine duct design and optimization," in $25^{\text {th }}$ International Congress of the Aeronautical Sciencies, (ICAS), Hamburg, Germany, 2006.

[17] F. Wallin, L. E. Eriksson, and M. Nillson "Intermediate turbine duct design and optimization," in $25^{\text {th }}$ International Congress of the Aeronautical Sciencies (ICAS), Hamburg, Germany, 2006.

[18] F. Wallin and L. E. Eriksson "Response surface based transitions duct shape optimization," in ASME Turbo-Expo, Power for Land, See and Air, Paper No. GT2006-90978, Barcelona, Spain, 2006.

[19] M. Babu, D. Bhatia, R. K. Shukla, A. M. Pradeep, and B. Roy, "Effect of turbine tip leakage flows on exhaust diffuser performance," in ASME Turbo-Expo, Power for Land, See and Air, Paper No. GT2011-45457, 2011. 